\title{
O narrador nos contos fantásticos de Borges e Cortázar
}

\author{
Maria Luiza Bonorino Machado
}

RÉSUMÉ: Le présent travail a pour objectif d'établir le profil des narrateurs des contes fantastiques de Jorge Luis Borges et Julio Cortazar. Cet essai tente prouver la différence du narrateur du fantastique par rapport au narrateur tradittionel. Le narrateur fantastique met em relief la vraissemblance pour garantir sa crédibilité.

MOTS-CLÉS: narrador, fantástico. Jorge Luis Borges, Júlio Cortazar.

Este artigo tem como objetivo fazer uma reflexão acerca do narrador nos contos fantásticos de Jorge Luís Borges e Júlio Cortázar. As obras desses dois escritores dispensam apresentação, por se tratarem de autores amplamente estudados, possuindo considerável fortuna crítica. O estudo aqui desenvolvido foi norteado pela possibilidade de estabelecer uma fisionomia própria para o narrador do conto fantástico latino-americano, tal qual tem sido proposto a partir dos anos 50. Buscaremos caracterizar esse narrador determinando seus traços dominantes.

Para demonstrar a singularidade do narrador do conto fantástico, selecionamos "O Aleph", "O Zahir" e "Tlön Uqbar Orbis Tertius" de Borges e "Distante", "Casa Tomada" e "Cefaléia” de Cortázar.

\section{O narrador}

O conto está ligado de forma direta ao ato de narrar. Nele a figura do narrador é que faz a mediação entre essa instância e o mundo narrado.

Maria Luiza Bonorino Machado é Doutora em Literatura Comparada - UFRGS 
Muito se tem discutido sobre a questão do narrador. Nomes de peso, como Saramago, afirmam que o narrador é o autor. Outros postulam o puro e simples desaparecimento dessa instância passando a palavra para as personagens, na tentativa de criar uma ilusão realista. Opondo-se a essas tendências, temos os teóricos Wolfgang Kayser e Wayne Booth. Para Kayser, para quem o narrador não é o autor; "mas um papel inventado e adotado pelo autor (...) um personagem de ficção no qual o autor está metamorfoseado". Kayser vê o narrador como criador mítico do universo. Para ele, o narrador ultrapassa a função de agente narrativo para adquirir poderes quase ilimitados na produção da obra ficcional.

Booth propõe a figura do autor implícito, uma espécie de gerenciador da obra, que não aparece em cena, mas que controla tudo. De acordo com Booth, mesmo o romance em que o narrador não é dramatizado cria a figura implícita de um autor, que está por trás das cenas, como um deus, puxando os cordões. O raciocínio empreendido por Booth nos leva a considerar a figura do narrador implícito, seja esse representado ou não, que tem como função fazer o relato do que ocorre na narrativa em sua totalidade. Para Booth, o autor implícito tem como atribuições escolher o foco narrativo, ordenar as ações, as personagens, o espaço e o tempo. É através da manipulação desses elementos que ele transmite seus valores.

Kayser, Booth e, também, Todorov, através da sua "imagem do narrador", propõem a existência de uma instância criadora que está além do narrador. O narrador se mostraria apenas como uma máscara, através da qual haveria todo um suporte que teria como atribuição escolher o foco, o discurso, alterar o narrador e sua função, gerenciar o estilo adequado.

Adotamos aqui a concepção que postula a existência do narrador, considerando essa instância vital para o bom funcionamento do elemento insólito dentro da obra.

\section{A questão da credibilidade do narrador}

Avaliar a confiabilidade do narrador é uma das questões mais importantes no que se refere aos contos fantásticos. Da autoridade estabelecida ou não pelo narrador depende a credibilidade da história narrada. Para Shlomit Kenan

A reliable narrator is one whose rendering of the story and commentary on it the reader supposed to take as an authoritative ac- 
count of the fictional truth. An un reliable narrator, on the other hand, is one whose rendering the story and/or commentary on it the reader has reasons to suspect. There are, of course, be different degrees of unrealiability. (...) Signs of unreability are perhaps easier to specify, and reability can the be negatively defined by their absence. The main sources of unreability are the narrator's limited knowledge, his personal involviment, and his problematic valuescheme. (p.100) ${ }^{1}$

A questão se complica quando estamos lidando com um narrador irônico como ocorre muitas vezes no texto borgeano. É difícil determinar até que ponto vai a ironia e quando ela afeta a própria credibilidade do narrador. A tarefa de distinguir entre um narrador confiável ou um narrador não confiável é em algumas obras muito difícil de ser levada a cabo. O leitor é levado a oscilar entre crer ou não naquilo que está sendo narrado. A hesitação própria do fantástico, tal como concebido por Todorov, ficaria aqui representada. Um excelente exemplo dado por Shlomit Kenan é o caso da governanta em A Volta do Parafuso de Henry James, que pode ser vista como um narrador confiável, contando a história de duas crianças perseguidas por terríveis assombrações, mas também pode ser considerada nãoconfiável, com um narrador com problemas mentais que relata inconscientemente seus próprios delírios e alucinações.

Para instrumentalizar a análise dos contos selecionados, adoto aqui a classificação de narradores proposta por Gérard Gennete em seu livro Discurso da narrativa. ${ }^{3}$ Nesta obra, o crítico propõe a seguinte categorização: uma primeira divisão entre o que chama de narrador intradiegético e extradiegético. $\mathrm{O}$ narrador do tipo intradiegético é aquele em que uma personagem assume a responsabilidade pela voz do narrador, contando a história de dentro da narrativa. O narrador extradiegético não possui representação na narrativa. O sujeito textual, que toma a palavra para narrar, permanece oculto. O narrador intradiegético possui subdivisões, são elas: homodiegético, autodiegético e heterodiegético. O narrador homodiegético ocorre em textos em que a personagem tem participação na história que está sendo contada. O narrador autodiegético acontece quando a história é contada pela personagem principal. E, por fim, o narrador heterodiegético, que se apresenta como uma personagem que conta uma história da qual não participou.

${ }^{1}$ RIMMON-KENAN, Schlomith. Narrative fiction: contemporary poetics. London: Metheun, 1983.

${ }^{2}$ GENETTE, Gerard. Discurso da narrativa. Lisboa: Vega, 1995.

${ }^{3}$ BORGES, Jorge Luis. O Aleph. São Paulo: Globo, 1995. 


\section{Jorge Luis Borges (1899-1986)}

\subsection{O aleph}

O narrador desse conto se constitui em personagem protagonista, um narrador autodiegético. Ele se apresenta como Borges, escritor, que se consagra à memória da mulher que em vida o rejeitou. A voz do narrador é dominante no conto, abrindo espaço para uma resenha no último bloco, embutida dentro de um discurso em primeira pessoa. Também, em primeira pessoa, são transcritas falas e observações de Carlos Argentino Daneri. Esse jogo entre as primeiras pessoas dá mobilidade ao texto; no entanto, o narrador possui poder absoluto, em nenhum momento ele deixa de marcar que está presente.

O fato de o narrador trazer o mesmo nome do autor e, também, ser escritor é um recurso para quebrar os limites entre a ficção e a realidade, apelando para um reforço extratextual da verossimilhança. O leitor faz, dessa forma, a correlação entre ficção e realidade, aceitando o tom autobiográfico do relato, o que reitera a autoridade do narrador.

Entretanto, a confiabilidade desse narrador é duvidosa. Por um lado, temos seu envolvimento emocional com a amada morta. Trata-se de um envolvimento que ele tenta negar através de uma visão crítica:

De resto, todos esses Viterbo... Beatriz (eu mesmo costumo repetir isso) era uma mulher, uma menina de uma clarividência quase implacável, mas havia nela negligências, distrações, desdéns, verdadeiras crueldades, que talvez reclamassem uma explicação patológica. (p.123) $)^{4}$

Essa tentativa de objetividade e lucidez tem a ver com a preservação da imagem do narrador diante do leitor, o que se liga à questão da confiabilidade. Outro dado a ser levado em consideração é seu ódio por Daneri, primo de Beatriz, com quem ela teve um caso revelado ao narrador através da visão que o Aleph proporcionou.

A brincadeira com a impostação poética é irônica, um fator que aumenta a falta de confiabilidade do narrador. A mofa com a instituição literária corrobora esse fato. Essa postura é uma característica de parte da produção de Borges. Carlos Argentino Daneri é o protótipo do louco literário, do literato pedante, que tem como obsessão realizar uma obra grandiosa e consegue não apenas publicar mas, também, o reconhecimento das instituições.

${ }^{4}$ TODOROV, Tzvetan. Introdução à literatura fantástica. São Paulo: Perspectiva, 1975. 
Pelas manifestações descritas: a negação do amor manifestado inicialmente e a aversão ou ódio, esse narrador tem como ponto de destaque a expressão de sua subjetividade; ele possui um envolvimento pessoal ao narrar: "A loucura de Carlos Argentino encheu-me de maligna felicidade, no fundo, sempre nos havíamos detestado.” (p.123).

Levando mais longe esse aspecto subjetivo, o narrador se vinga de Daneri. Essa atitude, pela sua pequenez, se por um lado humaniza o narrador, por outro o rebaixa diante dos olhos do leitor, podendo se constituir em fator de perda da confiabilidade.

\subsection{Tlön Uqbar Orbis Tertius}

Esse texto tem a estrutura de um conto policial. O narrador desse conto constrói a verossimilhança pela mistura de elementos reais e elementos ficcionais. Trata-se de um narrador testemunha que arrola outras testemunhas. São citados amigos de Borges que efetivamente existem ou existiram, como Bioy Casares, com quem desenvolveu um amplo trabalho durante determinado período, além da presença de Nestor Ibarra, Carlos Mastronardi, Ezequiel Martinez Estrada, etc. A mistura entre pessoas reais e fatos fictícios faz com que o leitor aceite com maior facilidade a presença do insólito, uma vez que esse é avalizado por tantas testemunhas confiáveis, entre estas o próprio autor metamorfoseado em narrador.

A narração em primeira pessoa revela, no começo, um narrador homodiegético que vai se transformar, em seguida, em heterodiegético, transitando de uma posição para outra na medida em que vai construindo o texto. Essa mobilidade é determinada pelo andamento da própria história. O narrador compartilha a solução de um mistério passo a passo, sem se deter demasiadamente em sua participação no caso, apenas o necessário para fazer o enredo avançar. A presença desse narrador-testemunha é dominante na obra do autor argentino. Esse tipo de narrador aparece em 40 contos e sua função é a de garantir a estruturação do elemento fantástico como ocorre nessa narrativa. É a visão dos fatos desse narrador que nos permite descobrir o elemento fantástico a partir daquilo que seria apenas uma estranheza.

\subsection{O zahir}

O narrador de "O zahir" se apresenta como sendo Borges. Sua voz é dominante no conto e tem a característica de ser a de um homem culto, procurando uma solução para o problema que o atormenta. Esse narrador, cuja voz se manifesta de diversas formas, possui um grau de conhecimento variável. Ele mantém com a história que narra uma relação que se apresenta ora como autodiegética, ora como diegética. A princípio, ele se manifes- 
ta como um narrador autodiegético que vai contar suas próprias experiências como personagem principal da história. Segundo Todorov ${ }^{5}$, esse tipo de narrador é característico do fantástico, pois "facilita a necessária identificação do leitor com os personagens” (p.94). Entretanto, no caso do texto aqui analisado, o narrador não é capaz de relatar os eventos com precisão, pois sua própria identidade se encontra ameaçada: "Não sou o que então eu era, mas ainda me é dado recordar, e talvez contar o ocorrido. Se bem que parcialmente, ainda sou Borges". (p.79) Em outros momentos, ele adota uma focalização onisciente e conta fatos a partir de uma visão ulterior à história, antecipando coisas que acontecerão. Quando nos remete aos textos sobre o zahir, a posição do narrador se modifica. Passa de narradortestemunha para narrador-resenhista. O efeito geral é de um narrador que se quer imparcial, mas a sombra da loucura projetada pelo zahir leva o leitor a suspeitar que seu testemunho já esteja comprometido, afinal, ele é, parcialmente, Borges. O narrador compromete dessa forma sua própria narrativa, uma vez que ela se apresenta com um determinado grau de nãoconfiabilidade diante da situação mental de quem conta, constituindo-se num caso de narrador com conhecimento limitado ou prejudicado. A própria estrutura da história mostra-se extremamente frágil e aponta para uma abertura, uma inconclusão, pois ela não nos é totalmente contada, apenas conjecturada pelo narrador.

O primeiro recurso utilizado para dar confiabilidade ao narrador é seu nome: Borges. Como já vimos anteriormente, esse jogo leva o leitor a fazer a correlação entre o escritor Borges e o narrador Borges. A confusão entre autor e narrador leva o leitor a reforçar a autoridade do narrador do conto, como se fosse um depoimento pessoal do escritor Borges, preparando-o assim para aceitar o elemento fantástico. Dessa forma, quebra-se a barreira entre ficção e realidade, e o conto atinge um estatuto diferenciado quando da sua recepção.

O segundo recurso de reforço da verossimilhança e maior grau de confiabilidade é a história de Teodelina Villar. Trata-se de um relato secundário, dotado de um paralelismo com a história do narrador, que servirá para introduzir a história do zahir. A vida de Teodelina está repleta de dados verificáveis, como a localização espacial de eventos, bairros onde morou, referência à Segunda Guerra Mundial. São fragmentos de realidade dentro do discurso.

Outra maneira de dar confiabilidade ao narrador e, portanto, ao texto que narra, é o uso de citações. Em O Zahir, encontramos citação da obra de Barlach, uma monografia sobre a moeda. É uma forma de transformar o texto em documento, atribuindo-lhe um valor maior do que ele realmente tem, com a intenção de torná-lo o mais realista possível. Borges utiliza as 
notas de rodapé para deixar o texto de Barlach mais verossímil ainda. $\mathrm{O}$ uso de notas de rodapé em um trabalho de ficção não é usual e automaticamente atrai a atenção para a presença de um narrador refletindo sobre sua própria narração. Além disso, a nota de rodapé coloca como ênfase o status do texto como artifício, promovendo reflexões sobre a textualidade e ficcionalidade, que são típicas de autoconsciências narrativas. Esse acúmulo de dados, esse ataque de erudição maciça tem como objetivo apagar as fronteiras entre o real e o irreal.

Outro recurso utilizado é o texto dentro do texto. O texto borgeano costuma apresentar essa característica. Usa as metanarrativas e lança mão da intertextualidade. O crítico Emir Monegal chama esse tipo de construção de "mise en abîme", pois é um texto crivado de alusões, menções, citações de outros textos que transparecem em sua superfície. Essa erudição passada pelo texto reforça a credibilidade mostrando que o narrador é extremamente culto e sofisticado, o que leva por associação (valores positivos) a pensar que é confiável.

Além do texto de Barlach, há outro texto que não é dado, mas que insinua o próprio conto fantástico escrito pelo narrador. Esse conto, assumindo a característica de ser ficção dentro da obra ficcional, modifica o caráter dessa última, atribuindo-lhe um estatuto não-ficcional, o que vem ao encontro do projeto borgeano de apagar as fronteiras entre a realidade e a ficção, dando ao narrador, dessa forma, a aparência de autor. Portanto, a sua autoridade é reforçada, ganhando em confiabilidade o que perde ao se humanizar.

\section{Júlio Cortázar (1914-1984)}

\subsection{Distante}

O conto "Distante" está estruturado em dois blocos distintos. O primeiro deles tem a forma de um diário, apresentado por um narrador autodiegético. Diários são testemunhas de vida, um espaço que o "eu" dispõe para se expressar sem censuras. $O$ fato de escolher essa forma marca uma opção pelo discurso interno, pela verdade individual, além de carregar o texto com o peso do efetivamente vivido, atribuindo-lhe verossimilhança sem deixar de preservar um espaço para a fantasia e o delírio. Textos em forma de diário funcionam para o leitor como testemunhas autorizadas a narrar, possuem a autoridade do documento, da experiência, atravessando o fino véu que separa a realidade interna da realidade externa.

O segundo bloco assume a forma de um relato com narrador extradiegético, narrando de fora, um enfoque externo. Trata-se de um narrador que se apresenta como confiável, pois dá acesso a dados concretos 
da viagem da protagonista a Budapeste, mostrando detalhes da paisagem. Ele constrói uma verossimilhança externa que corresponde à verossimilhança interna do diário; dá corpo concreto às fantasias da protagonista. Dessa relação surge sua confiabilidade e a própria construção do fantástico.

$\mathrm{Na}$ cena final, ele narra objetivamente a troca de lugares entre Alina Reyes e a mendiga na ponte. A opção pelo enfoque externo, a troca de narradores, revela-se uma estratégia para dar maior credibilidade ao insólito narrado. Uma narrativa do ângulo interno da protagonista afetaria sua credibilidade e poderia ser tomada como um distúrbio de personalidade, destruindo o fantástico. O caráter da narrativa depende exclusivamente da atuação do narrador, que para preservar o efeito insólito muda de forma, de ângulo.

\subsection{Cefaléia}

Esse conto começa com uma nota de agradecimento, que pretende emprestar verossimilhança à história, pois é dirigida às autoridades médicas, ou seja, alguém digno de confiança e que, aparentemente (ainda não se sabe), não faz parte do universo ficcional. Essa nota também tem como objetivo atestar a sobrevivência e a sanidade dos protagonistas. Trata-se de uma estratégia utilizada para qualificar o narrador, bem como o resto do conto e está redigida na primeira pessoa do plural numa narrativa que apresenta um narrador homodiegético.

O fantástico produzido por esse conto vem, em parte, desta forma de articulação do narrador, que deixa sempre impreciso o número de personagens e o seu sexo. Se por um lado essa imprecisão corrobora na elaboração do efeito insólito, por outro lado não ter um perfil individual coloca em risco sua credibilidade, pois não se sabe quem está narrando.

No conto "Cefaléia" são descritos uma série de sintomas que não podem ser associados a doenças conhecidas, parecendo mais puros delírios, que recebem designação própria dentro da narrativa, na qual ocorre a ressignificação de palavras latinas. Esse recurso tenta dar veracidade às estranhas doenças transmitidas pelas manscúspias, animais da invenção de Cortázar.

A ambigüidade e a imprecisão do narrador, em contar o que de fato acontece na chácara onde criam os animais, transmitem ao conto seu fascínio, articulando o fantástico.

\subsection{Casa Tomada}

O narrador de "Casa Tomada" pode ser classificado como não-confiável. Tal afirmativa se deve ao fato de poder passar horas absorvido na atividade mecânica da irmã, o tricô, e ainda achar isso bonito. Uma atitude ensimes- 
mada e completamente obsessiva, típica de um apaixonado. E assim como o ódio, a paixão o torna um narrador suspeito, pois ocorre o envolvimento pessoal.

Nada nos garante que os fatos narrados não sejam resultado de sua visão distorcida, pois é ele quem denuncia a tomada da casa, é ele e apenas ele que ouve os barulhos. Irene, sua irmã, apenas acredita em sua palavra e passa a se comportar de acordo, fazendo tudo o que o irmão espera dela. Entretanto, buscar uma explicação através de uma crise alucinatória seria dissolver o elemento fantástico.

Esse narrador oscila entre autodiegético, pois conta uma história que acontece consigo mesmo, mas, ao mesmo tempo, é heterodiegético, porque transforma a irmã e a casa em personagens principais da narrativa. Diz que ele mesmo não tem importância e que importante é falar da casa e de Irene. No entanto, Irene é uma cópia feminina do narrador. Ela tece suas coisas. Ele tece o conto. Compartilham o mesmo passado, o mesmo espaço, os mesmos hábitos repetitivos. São como uma imagem diante do espelho. $\mathrm{O}$ ato de tecer acaba para Irene no instante em que ambos abandonam a casa tomada por ruídos. Mas começa para o narrador a tessitura do texto que é o ato de rememorar.

\section{5 - Conclusão}

À primeira vista, o que chama a atenção nos contos aqui analisados é a quantidade e a variedade de narradores e focalizações. Para dar conta de uma narrativa que se esfacela é feito um esforço em direção à construção de sentido, o que requer enfoques diferentes tendo em vista o efeito fantástico dos textos. Essa fragmentação do narrador em diversas categorias dentro de um único texto, própria do texto pós-moderno, está ligada, de maneira mais ampla, com o percurso do sujeito através da História. De senhor da razão, centro absoluto, ele se transforma, não é mais o pólo irradiador dos acontecimentos e perde a autoridade sobre o que acontece a sua volta como bem nos mostra Walter Benjamin. O que acontece é que a identidade da experiência foi desintegrada enquanto linearidade, que só a postura do narrador permite. Essa grande diversidade de narradores dentro dos contos fantásticos visa garantir uma estrutura verossimilhante, ainda que essa não se apresente de forma linear. A verossimilhança tornou-se convenção artística ligada a um código estético de determinada época. No fantástico, ela se apresenta na corda bamba, serve de moldura para o efeito insólito, promovendo a base que levará o leitor a questionar a realidade. Entretanto, não pode ser reduzida a um elemento a mais dentro do grande jogo que o 
fantástico articula. Trata-se de um fator fundamental, pois ligado ao conceito de verossimilhança encontra-se o de confiabilidade e ambos estão associados ao efeito de estranhamento causado pela narrativa. Do bom funcionamento de uma estrutura verossimilhante depende inteiramente o fantástico para atingir seus objetivos.

Os contos de Cortázar possuem um traço em comum: o caráter de expulsão, de oposição ao outro. A narrativa se constrói dentro da subjetividade das personagens. Os contos de Borges são feitos tomando por base a racionalidade, aquilo que o autor denominou "estrutura vigorosa", ou seja, o real é caótico, não tem lógica alguma em sua organização, mas um conto é um artifício e como tal deve funcionar de maneira perfeita, possuindo uma lógica interna irrepreensível.

Pela análise dos contos, vimos que o narrador do conto fantástico tem uma preocupação muito grande com sua confiabilidade. Mesmo aqueles narradores que podem ser caracterizados como não-confiáveis utilizam recursos textuais a fim de que sua autoridade seja levada em conta pelo leitor de forma a ser tomado como alguém qualificado para narrar. Essa preocupação com a confiabilidade faz brotar estratégias dentro da fragmentação do narrador: é a narrativa em forma de diário, citações, notas de rodapé, nota de agradecimento, o texto dentro do texto, etc. O narrador busca de todas as formas atestar sua autoridade diante do leitor. Ele precisa do leitor, pois esse desempenha um papel fundamental. É um leitor que se vê obrigado a participar da trama, o leitor "cúmplice" de que falava Cortázar, pois de sua leitura depende, em parte, a constituição do próprio fantástico. O leitor colabora, faz parte da história, é um leitor desacomodado, que é exigido o tempo todo. Ele deve preencher as lacunas deixadas na narrativa, ligar as pontas soltas, completar com sua imaginação aquilo que não é dito, mas sugerido e, às vezes, nem isso sequer como acontece com as conjecturas finais do narrador de "O Zahir". Esse aspecto é uma característica do fantástico latino-americano. O leitor do texto realista tradicional se mostra "acomodado", pois segue sem vacilações o fio da narrativa, confiando em todas as informações que lhe são fornecidas, pois essas encontram amparo em sua experiência de mundo.

Borges e Cortázar, apesar do tratamento diferenciado conferido ao fantástico, se valem de estratégias textuais distintas, mas essas têm o mesmo objetivo, que é garantir a verossimilhança e com ela a confiabilidade, o que nos leva a refletir sobre o caráter do narrador dos contos fantásticos como aquele que tem seu traço relevante no fato de colocar sua ênfase nesse aspecto. Essa é a sua principal característica.

A narrativa realista tradicional costuma estabelecer de forma bastante clara a diferença entre aquilo que é real e aquilo que é imaginário. Pela 
análise dos contos aqui apresentada, constata-se que as narrativas fantásticas de Borges e Cortázar questionam esse modo de organização textual pois, a todo momento, o narrador promove rupturas nessas categorias, gerando a desordem. Assim como promove rupturas, especialmente pela introdução do elemento insólito, o narrador restabelece o equilíbrio instaurando uma lógica outra, que é dotada de coerência interna originada da própria natureza da ruptura ou do elemento fantástico.

Pelo o que foi exposto, concluo que os narradores aqui analisados têm uma fisionomia que lhes é própria, procuram a todo custo manter a verossimilhança e com ela a confiabilidade, preocupando-se ao mesmo tempo com a ambigüidade, sendo em última instância responsáveis junto com o leitor, ao qual dispensa uma atenção especial, pela instauração do fantástico na narrativa. 